\title{
UNA APROXIMACION LEGAL A LA CONJUNCION DE MOBILIARIO DE USO HOSTELERO CON EL PAISAJE Y PATRIMONIO CULTURAL EN CORDOBA
}

\author{
ANTONIO ALVAREZ SALCEDO \\ Abogado \\ HOSTELEY abogados ${ }^{1}$
}

\begin{abstract}
La Carta internacional sobre turismo cultural adoptada por ICOMOS en la $12^{\mathrm{a}}$ Asamblea General en México, en octubre de 1999, bajo el lema "La Gestión del turismo en los sitios con Patrimonio Significativo (1999)” define PATRIMONIO como un concepto amplio que incluye tanto los entornos naturales, como los culturales y dentro de ambos abarca el PAISAJE, además de los sitios históricos, los emplazamientos, los entornos construidos, amén de otros aspectos como los grupos de objetos, tradiciones, biodiversidad y las experiencias vitales.
\end{abstract}

La Carta hace especial hincapié en la interacción dinámica entre el turismo y el patrimonio cultural. Precisamente por constituir un punto de referencia dinámico y ser instrumento de crecimiento y de intercambio, el objetivo fundamental, según la carta, de la gestión del patrimonio es precisamente comunicar su significado y la necesidad de su conservación, tanto a la comunidad anfitriona como a los visitantes. Esto conlleva la obligación de respetar los paisajes y las culturas a partir de los cuales se ha desarrollado el patrimonio.

Establece que el turismo es cada vez más apreciado como una fuerza positiva para la conservación de la cultura y el turismo es un factor esencial para muchas economías nacionales y locales. Es un importante factor de desarrollo siempre que se gestione adecuadamente ofreciendo numerosas oportunidades y posibilidades.

Un turismo cultural excesivo o mal gestionado, con cortedad de miras, así como un turismo considerado como simple crecimiento pueden poner en peligro la naturaleza física del patrimonio cultural, su integridad y sus características identificativas. Por el contrario, un turismo cultural bien gestionado debería de aportar beneficios a la comunidad anfitriona, proporcionando medios y motivaciones para cuidar y mantener ese patrimonio, dando lugar a una industria turística sostenible y aumentando la protección sobre los recursos del patrimonio cultural en beneficio de las generaciones futuras.

Por ello en su introducción ya nos deja establecidas las que podemos considerar como recomendaciones pragmáticas en cuanto al turismo cultural:

\footnotetext{
${ }^{1}$ info@hosteley.com
} 
- $\quad$ El paisaje forma parte del patrimonio cultural y debe ser objetivo fundamental el comunicar su significado y la necesidad de su conservación a los visitantes

\author{
- $\quad$ El turismo es una fuerza positiva para la conservación de la cultura \\ - $\quad$ El turismo es un factor esencial para muchas economías nacionales y \\ locales \\ - $\quad$ El Turismo cultural bien gestionado debe de aportar beneficios a la \\ comunidad anfitriona
}

Concretamente en el principio segundo se argumenta, como la relación entre los sitios con patrimonio y el turismo es una relación dinámica y puede implicar valoraciones encontradas. Esta relación debería gestionarse de modo sostenible para la actual y para las futuras generaciones. Este principio es el que precisa en su aplicación práctica de más desarrollo y de más concertación entre los agentes implicados. Esas valoraciones encontradas en la relación patrimonio y turismo, entendidos ambos conceptos de forma amplia, supone conjugar los interés de muchas personas y colectivos. Intereses que bien gestionados supondrán un modelo sostenible de relación para el futuro. Así una parte de esa relación dinámica es la explotación turística en determinadas calles del casco histórico, patrimonio de la humanidad, en su proyección y modalidad de la utilización del espacio público con mobiliario para la prestación de servicios de hostelería que deberá aunar los intereses públicos y privados para ser sostenible. La Carta efectúa una llamada a los poderes públicos para que dentro de las políticas sociales y económicas, culturales y turísticas, la protección y conservación de los sitios con patrimonio contenga un componente esencial.

Recomienda que los proyectos turísticos, sus actividades y su desarrollo debieran conseguir resultados positivos y minimizar los impactos negativos para el patrimonio y para los modos de vida de la comunidad anfitriona, al mismo tiempo que deberían de responder a las necesidades y expectativas del visitante. Habrían de tenerse en cuenta tres factores: los impactos del turismo y sus actividades en el patrimonio cultural y por tanto en sus entornos y en el paisaje cultural; los impactos del turismo en el modo de vida de los ciudadanos y de sus barrios; y las necesidades y expectativas del visitante. Los distintos sistemas de evaluación, las encuestas, los índices de medición que se puedan adoptar responderán entre otras a las siguientes preguntas: ¿les parece excesivo la utilización de las vías públicas del casco histórico con mobiliario de hostelería?; ¿les resulta negativo el impacto de la publicidad de los establecimientos?; ¿creen que estaría mejor el casco histórico sin la presencia de ese mobiliario?; ¿es suficiente para atender las necesidades del visitante?, ¿el mobiliario de las terrazas de establecimientos de comidas y bebidas responde a las necesidades del visitante? Y a través de una valoración de los resultados minimizar los impactos negativos para el patrimonio. La Carta en el apartado séptimo de este principio segundo establece que deberían elaborarse programas de evaluación continua para valorar los impactos progresivos de las actividades turísticas de los planes de desarrollo en cada sitio o comunidad

En el apartado cuarto del principio segundo se establece como principio el de conservar la autenticidad en los sitios del Patrimonio. Tal vez en este punto sería conveniente 
una reflexión sobre la oferta de ocio y en este caso de prestación del servicio de comidas y bebidas es decir la gastronomía, preguntarse ¿Qué espera el turista en su visita a un destino patrimonial?, ¿es más conveniente la apuesta por una oferta gastronómica tradicional con más o menos innovación, es decir una gastronomía local en un espacio histórico Patrimonio de la Humanidad con mayor presencia en el espacio público y en el paisaje, mediante elementos de mobiliario y publicidad (cartelería, mesas, sillas, barriles, etc) o tiene cabida la oferta importada de la comida fast food o de otros orígenes (como italiana, china, tailandesa, etc)?.No cabe duda que la libertad de empresa y las preferencias del cliente- turista marcaran el camino, pero se puede correr el riesgo de convertirse el sitio de patrimonio en un parque temático carente de autenticidad.

Continúa en el apartado quinto de este principio segundo estableciendo que los proyectos de infraestructuras y los proyectos para el desarrollo turístico deberían tomar en cuenta la dimensión social estética y cultural los paisajes naturales y culturales, así como los amplios contextos visuales de los sitios con patrimonio. De nuevo el paisaje, la estética de los entornos está presente en el desarrollo turístico. Aquí se debe de reflexionar precisamente esa dimensión estética del paisaje cultural y el contexto visual en cuanto a la utilización del mobiliario en los espacios públicos y en cuanto a los materiales, en cuanto a sus colores, en cuanto a la cantidad de información gráfica y visual que se ofrece mediante listas de precios, mediante cartelería, en algunos casos cartelería fotográfica, que en algunos casos rompen totalmente la estética de esa arquitectura local del lugar y del paisaje.

Por otra parte el principio número tres de la carta del ICOMOS sobre patrimonio cultural se refiere a la planificación de la conservación y del turismo de forma que se garantice que la experiencia del visitante le merezca la pena y le sea satisfactoria y agradable. En el apartado segundo de este principio tercero se establece como principio que los visitantes deberían poder experimentar los sitios con patrimonio de modo tranquilo y a su propio ritmo si este es su deseo. Es importante este apartado con introducción de esa posibilidad de disfrutar de la experiencia de forma tranquila ya su propio ritmo. Ello está en íntima conexión con la peatonalización, con la regulación de los horarios de carga y descarga, con la colocación en el espacio y en el tiempo del mobiliario de establecimientos públicos en la vía pública e incluso con la posibilidad, que establece el propio principio, de creación en caso de necesidad de viarios especiales de circulación de visitantes al efecto de minimizar los impactos sobre la integridad.

El Convenio Europeo del Paisaje de Florencia de 20 de octubre de 2000, en su preámbulo, establece que los Estados miembros del Consejo de Europa están preocupados por alcanzar un desarrollo sostenible basado en una relación equilibrada y armoniosa entre las necesidades sociales, la economía y el medio ambiente. Toma nota de que el paisaje desempeña un papel importante, de interés general en los campos, ecológico, cultural, medio ambiental y social y que constituye un recurso favorable para la actividad económica y que su protección, gestión y ordenación pueden contribuir a la creación del empleo. El paisaje es un elemento clave del bienestar individual y social y de que su protección, gestión y ordenación que implican derechos y responsabilidades para todos. 
En España el Artículo 46 de la Constitución Española establece que "los poderes públicos garantizarán la conservación y promoverán el enriquecimiento del patrimonio histórico, cultural y artístico de los pueblos de España y de los bienes que lo integran, cualquiera que sea su régimen jurídico y su titularidad. La ley penal sancionará los atentados contra este patrimonio".

De forma específica la Ley 16/1985, de 25 de junio, del Patrimonio Histórico Español en su artículo primero establece lo que es el objeto de la presente ley y es la protección, acrecentamiento y transmisión a las generaciones futuras del Patrimonio Histórico Español.

Así Integran el Patrimonio Histórico Español los inmuebles y objetos muebles de interés artístico, histórico, paleontológico, arqueológico, etnográfico, científico o técnico. También forman parte del mismo el patrimonio documental y bibliográfico, los yacimientos y zonas arqueológicas, así como los sitios naturales, jardines y parques, que tengan valor artístico, histórico o antropológico.

Ciertamente esta Ley del año 1985 no menciona el paisaje como si lo hizo la carta internacional sobre turismo cultural adoptada por ICOMOS en 1999. Aunque de su articulado se infiere su protección y así en su artículo cuatro establece una fórmula de protección que el código penal convertirá en delito como es la expoliación y los delitos sobre el patrimonio histórico (art. 321 a 324 CP) y así establece que se entiende por expoliación toda acción u omisión que ponga en peligro de pérdida o destrucción todos o alguno de los valores de los bienes que integran el Patrimonio Histórico Español, o perturbe el cumplimiento de su función social. Pero cuál es esa función social, ¿la contemplación del paisaje está incluida,?, Y por otra parte, hay que destacar que protege de la perturbación de su función social hasta el punto de que en su artículo séptimo ordena que "los Ayuntamientos cooperarán ....y notificarán a la Administración competente cualquier amenaza, daño o perturbación de su función social que tales bienes sufran, así como las dificultades y necesidades que tengan para el cuidado de estos bienes".

El artículo veinte en su apartado tercero establece que "La conservación de los Conjuntos Históricos declarados Bienes de Interés Cultural comporta el mantenimiento de la estructura urbana y arquitectónica, así como de las características generales de su ambiente”.

La Ley Orgánica 2/2007, de 19 de marzo, de reforma del Estatuto de Autonomía para Andalucía en su artículo 28,a diferencia de otra normativa estatal, establece de forma expresa como derecho universal el de disfrutar del paisaje en condiciones de igualdad y así mismo establece el uso responsable del mismo para evitar su deterioro y conservarlos para las generaciones futuras

Es decir por un lado declara el derecho al disfrute del paisaje, el ejercicio de este derecho de disfrute en condiciones de igualdad, la obligación de hacer un uso responsable del mismo evitando su deterioro y la obligación de conservarlo para las generaciones futuras. 
Por otra parte en el artículo 33 establece que todas las personas tienen derecho también al disfrute de los bienes patrimoniales artísticos y paisajísticos de Andalucía, en condiciones de igualdad; y al acceso a la cultura, estableciendo además en el mismo artículo el deber de respetar y preservar el patrimonio cultural andaluz.

El Estatuto de Autonomía establece que la ley desarrollará la obligación de todas las personas de, entre otras, la de "cuidar y proteger el patrimonio público especialmente el de carácter histórico artístico y natural”. Al tratar de los principios rectores, el estatuto, establece que los poderes de la Comunidad Autónoma orientarán sus políticas públicas a garantizar y asegurar el ejercicio de los derechos reconocidos en el capítulo anterior mediante la aplicación de los siguientes principios rectores: el fomento de los sectores turístico como elemento económico estratégico de Andalucía; el libre acceso de todas las personas a la cultura y el respeto a la diversidad cultural; en el decimo octavo el principio referido a la conservación y puesta en valor del patrimonio cultural histórico y artístico de Andalucía con especial referencia al flamenco.

La ley 14/2007 de Patrimonio Histórico de Andalucía es el ordenamiento jurídico propio autonómico para la protección del patrimonio histórico. Si bien esta Ley autonómica no nombra el paisaje como elemento del patrimonio cultural sí contiene, como novedad, en su artículo 19 una referencia clara y determinante a la contaminación visual o perceptiva y así establece una definición, cosa que no hace la Ley del Patrimonio Histórico nacional, de lo que se entiende por contaminación visual o perceptiva a los efectos de esta ley y es aquella intervención, uso o acción en el bien o en su entorno de protección que degrade los valores de un bien inmueble integrante del patrimonio histórico y toda interferencia que impida o distorsione su contemplación continua. Establece la obligación de los municipios en los que se encuentren bienes inscritos en el Catálogo General del Patrimonio Histórico de Andalucía de recoger en sus instrumentos de planeamiento urbanístico u ordenanza municipales de edificación y urbanización medidas que eviten su contaminación visual o perceptiva.

Tales medidas comprenderán, al menos, el control de los siguientes elementos:

a) Las construcciones o instalaciones de carácter permanente o temporal que por su altura, volumetría o distancia puedan perturbar su percepción.

b) Las instalaciones necesarias para los suministros, generación y consumo energéticos.

c) Las instalaciones necesarias para telecomunicaciones.

d) La colocación de rótulos, señales y publicidad exterior

e) e)La colocación de mobiliario urbano

f) La ubicación de elementos destinados a la recogida de residuos urbanos.

Por tanto el mobiliario de hostelería en espacios exteriores de vía pública que utilizan los establecimientos de hostelería para sus terrazas de veladores, los rótulos de los establecimientos, su publicidad exterior deberán ser controladas para evitar una contaminación visual o perceptiva a los efectos de esta Ley que degrade los valores de un bien 
inmueble integrante del patrimonio histórico y toda interferencia que impida o distorsione su contemplación continua.

En su artículo 33 se establece una prohibición análoga a la que se establece en la ley de patrimonio nacional al prohibir la publicidad en las fachadas de los monumentos y toda construcción que altere o perturbe la contemplación de bienes de interés cultural.

En el ámbito municipal la OM reguladora de la ocupación temporal de espacios exteriores con mobiliario de hostelería, tal como mesas, sillas, parasoles, es decir lo que comúnmente se viene llamando terrazas de veladores de Córdoba, en su exposición de motivos establece tres consideraciones importantes:

- $\quad$ Que las terrazas de veladores pueden constituir un beneficioso factor para aumentar la utilización y el disfrute por los ciudadanos de los espacios públicos y contribuir a convertirlos en lugar de estancia, convivencia y relación.

- $\quad$ La necesidad de una ordenación que garantice los intereses generales y los usos preferentes, la seguridad, la tranquilidad, el ornato públicos, el medio ambiente y el paisaje urbano, las características mismas de la ciudad y de cada zona, su ambiente

- $\quad$ El objetivo que se persigue es que las terrazas se integren armoniosa y discretamente en los espacios públicos, sin alterarlos, sin suponer un elemento que distorsione su composición o perturbe su función.

La Ordenanza municipal en su artículo cuatro otorga un carácter discrecional al otorgamiento de las licencias "de veladores" de forma que establece que solo se otorgaran cuando sean compatibles con los intereses generales y a tal determinación establece que se tendrán encuentra entre otros la preservación del paisaje urbano, de los ambientes y de las condiciones estéticas de los lugares y edificios, aunque no cuenten con ningún tipo de protección específica en las legislaciones sectoriales. Estableciendo unas limitaciones en su art 16 para la protección de estos valores y objetivos máxime cuando los lugares y edificios cuenten con protección específica o sean BIC. Así establece que no se autorizarán terrazas que menoscaben la contemplación, el disfrute o las características específicas y relevantes de espacios públicos, monumentos o edificios singulares, incluso aunque no cuenten con protección especial en virtud de la legislación de patrimonio histórico, ambiental o urbanística. Incluso cuando no proceda la simple denegación de la licencia por esta causa, se establecerán al otorgarla las restricciones pertinentes para que no comporte un detrimento de los valores estéticos, paisajísticos y ambientales que en cada caso haya que preservar.

Por esta razón podrán limitarse más allá de lo que se desprende de los restantes preceptos de dicha Ordenanza la superficie susceptible de ocupación, el tipo de mobiliario, el número de mesas o sillas, sus dimensiones, o prohibirse la instalación de toldos, sombrillas o cualquier otro elemento, especialmente cuando afecte a edificios o espacios protegidos. Además, las licencias podrán limitar la extensión total de la superficie ocupada por la terraza cuando, aun 
cumpliéndose las demás previsiones de esta Ordenanza, sea conveniente para preservar el uso característico o el ambiente de bulevares, plazas, calles peatonales, paseos u otros espacios similares o cuando su excesiva extensión o acumulación a otra u otras terrazas pueda constituir una degradación ambiental, estética o paisajística de la zona afectada.

Incluso al respecto de los requisitos generales del mobiliario que compone la terraza y por tanto susceptible de legalización, el art 20 establece una serie de medidas entre las que debemos destacar que en todo caso los elementos muebles que compongan la terraza "habrán de armonizar con el ambiente y carácter del entorno urbano en que se sitúe la terraza sin que en ningún caso perjudiquen el ornato público y las condiciones estéticas y ambientales por sus colores, tamaño o diseño, por la publicidad que incorporen o por cualquier otra característica”

Por tanto establece normas de protección del ambiente y carácter del entorno y también del paisaje al respecto de los colores del mobiliario, de su diseño y de la publicidad que pudieran contener

Además de las normas antes mencionadas que son de carácter general la OM establece la posibilidad de adoptar normas o criterios específicos para determinadas zonas que por sus valores merezcan una especial protección tales como:

- $\quad$ El establecimiento de número, ubicación y superficie máxima de las terrazas autorizables, así como, en su caso, distribución entre los distintos establecimientos.

- $\quad$ Establecimiento de características técnicas, estéticas o de otro tipo.

- $\quad$ Limitación del tipo de elementos que puedan formar las terrazas.

- $\quad$ Prohibición de publicidad en los elementos que compongan las terrazas.

- $\quad$ Tipos normalizados del mobiliario.

- Informes preceptivos de la Oficina Municipal del Casco Histórico u otros que se estimen especialmente adecuados para garantizar los intereses en juego

En cuanto a la publicidad la OM de publicidad exterior de córdoba(B.O.P. n ${ }^{\circ}$ 65, de 20 marzo de 1990)entiende por publicidad, a estos efectos, toda forma de comunicación realizada por una persona física o jurídica, pública o privada, en el ejercicio de una actividad comercial, industrial, artesanal o profesional, con el fin de promover de forma directa o indirecta la contratación de bienes muebles o inmuebles, servicios, derechos y obligaciones.

Muy frecuentemente los establecimientos de hostelería acuden a esta publicidad como para comunicar, no ya la existencia, nombre e incluso especialidad gastronómica que ofertan sino, toda su oferta gastronómica y ofertas puntuales y precios. 
A este respecto hay que mencionar que la el decreto 198/1987 de la junta de Andalucía establece que en el exterior de los establecimientos deberá existir una carta de comidas y bebidas cuando se trate de restaurantes, lo que aun siendo de imperativo legal no deja de ser una publicidad no voluntaria para el establecimiento, obligado por esta norma que como veremos a continuación puede incluso contradecirse con los dictados de la propia OM que en el casco histórico establece claras restricciones en la publicidad de las fachadas de establecimientos públicos.

Para la OM es publicidad exterior aquella modalidad de actividad publicitaria que utiliza, como vehículo transmisor del mensaje, medios materiales de diversa índole, susceptibles de atraer la atención de cuantas personas se encuentran en espacios abiertos, transitan por calles o plazas, circulan por vías de comunicación, utilizan medios colectivos de transporte y, en general, permanecen o discurren en lugares o por ámbitos de utilización general.

Con carácter meramente enunciativo establece la OM que se reputará publicidad exterior toda representación gráfica o texto publicitario que se presente en soportes situados en las fachadas, medianeras, cerramientos, postes, farolas, columnas, etc., de los centros urbanos o en el campo; anuncios luminosos, permanentes o intermitentes, de iluminación propia o reflectante, total o parcialmente publicitarios.

También con carácter general establece la OM que queda prohibida la publicidad entre otros:

a. Sobre bienes declarados de interés cultural, al tratarse de Monumentos, Jardines, Conjuntos y Sitios Históricos, así como Zonas Arqueológicas de conformidad con la Ley 16/1985, de 25 de Junio, de Patrimonio Histórico Español y demás legislación complementaria y autonómica sobre esta materia.

b. Sobre los templos dedicados al culto, aunque no ostenten la calificación prevista en el apartado a) de este número, en los cementerios y sobre las estatuas de plazas, vías y parques públicos.

c. En aquellas áreas o sectores que puedan impedir o dificultar la contemplación de los edificios o espacios enumerados en los apartados a).

Verdaderamente importantes los tres ámbitos donde se prohíbe la publicidad pero especialmente llama la atención el tercero, por su relación con el paisaje, con el entorno de gran parte de los hitos turísticos de la ciudad. 
Con carácter general, sin perjuicio de lo que se dispone en esta Ordenanza para cada modalidad publicitaria, no se permite la fijación directa de carteles sobre edificios, muros, vallas y cercas, sino que habrán de ser utilizados soportes exteriores y otros medios de fijación.

La colocación de rótulos, anuncios, carteles, banderas, etc., en los establecimientos comerciales, industriales y de servicios sitos en el Casco Histórico de la ciudad se regulará por lo previsto en el Capítulo XI de esta Ordenanza y por la Ordenanza Municipal del Casco Histórico.

En la regulación de la publicidad en establecimientos el art. 36 establece:

1. Queda taxativamente prohibida la instalación de soportes publicitarios cuyos elementos sean de acero, aluminio, etc., que no tengan un tratamiento o pintado adicional acorde con los materiales tradicionales, así como los materiales plásticos y los rótulos luminosos.

2. Puede emplearse rótulos en forma de bandera, en materiales metálicos en las condiciones señaladas en el apartado anterior o de madera, siempre que no sobresalgan del ancho del acerado y con un vuelo máximo de 75 centímetros.

3. Asimismo, se permiten los rótulos murales en fachadas únicamente en planta baja, haciéndolos coincidir sobre los huecos y con una altura máxima de 50 centímetros, de los mismos materiales previstos en el apartado anterior.

4. Solo podrá establecerse por cada local o establecimiento un rótulo o, en su caso, uno de bandera.

El ejercicio de la publicidad exterior, en lo que se refiere a los aspectos regulados en esta Ordenanza, se sujeta a licencia y/o autorización municipal, en los términos previstos en la propia Ordenanza para cada tipo de publicidad.. En todo caso, la colocación de rótulos, anuncios, y cualquier publicidad en el Casco Histórico está sujeta a Licencia Municipal de Obra Menor.

Todas estas consideraciones en una ciudad en la que el turismo cultural es uno de sus motores de desarrollo, con el mayor casco histórico declarado patrimonio de la humanidad, con 103 bienes de interés cultural entre conjunto histórico, monumentos, zona arqueológica y bienes de categoría general, ubicados en las zonas de transito turístico, un bien declarado monumento natural de Andalucía como son los Sotos de la Albolafia, con un flujo de casi un millón de turistas anuales dentro de ese medio y ámbito territorial, con una densidad de instalaciones de hostelería dentro de ese ámbito muy alta, no puede permanecer impasible ante esas circunstancias si pretende un turismo sostenible en el futuro y que efectivamente se protejan los intereses de todos, las expectativas futuras, y que siga siendo el patrimonio y el paisaje en este caso fundamentalmente cultural un elemento dinamizador y que cumpla su función social-. 